\title{
Mieloma múltiple con metástasis cutáneas y testiculares recurrente después trasplante autólogo de médula ósea: relato de caso
} Multiple myeloma with recurrent skin and testis
metastases after an autologous bone marrow
transplantation: report of a case

Correspondencia Thaís B. Brandenburg thaisbyanca@gmail.com

Recibido: 24/02/2019

Arbitrado por pares

Aprobado: 26/06/2019

Citar como: Brandenburg TB, Zanini $J C$, Schossler-Loss F. Mieloma múltiple con metástasis cutáneas y testiculares recurrente después trasplante autólogo de médula ósea: relato de caso. Acta Med Peru. 2019;36(4):291-5
Thaís B. Brandenburg1, Júlio C. Zanini2,a , Francisco Schossler-Loss

1 Centro Universitário da Fundação Assis Gurgacz. Cascavel, Brasil.

2 Hospital do Cáncer Uopeccan. Cascavel, Brasil.

a Cirujano oncólogo

\section{RESUMEN}

Se relata el caso de un paciente masculino de 56 años con mieloma múltiple (MM) y presencia de plasmocitomas en tejido celular subcutáneo y en testículo. El paciente tenía el antecedente de MM tratado con quimioterapia y trasplante autólogo de médula ósea y que después de 4 años de remisión de la enfermedad presentó recidiva ósea, la misma que fue tratada con quimioterapia e inmunoterapia. No hubo respuesta satisfactoria a los primeros ciclos del tratamiento con progresión de la enfermedad ósea y surgimiento de nódulos en dorso, puño y testículo sospechosos de recidiva de la enfermedad. Se procedió a resección de las lesiones en el dorso y puño que, en el examen anatomopatológico, fueron compatibles con neoplasia maligna y la prueba de inmunohistoquímica confirmó que se trataba de metástasis del MM. Se optó por la continuidad del tratamiento hasta completar los 12 ciclos propuestos, pero no hubo mejoría de las lesiones además de la aparición de nuevas lesiones en tejido celular subcutáneo y región perianal, con empeoramiento clínico. El paciente falleció después de dos meses de cuidados paliativos.

Palabras clave: Mieloma múltiple; Metástasis; Plasmocitoma; Tumores cutáneos; Neoplasias testiculares (fuente: DeCS).

\section{ABSTRACT}

We present the case of a 56-year old male subject with multiple myeloma (MM) and with plasmacytomas in both the subcutaneous tissues and testis. He had a past history of MM who underwent chemotherapy and autologous bone marrow transplantation. After four years with disease remission, he presented with bone relapse, and he received chemotherapy and immunotherapy. There was no satisfactory response to the first cycles of therapy, and there was progression of bone disease, and nodes suspicious of disease recurrence arose in the back, fists, and testes. Both back and fist lesions were resected. The anatomopathological examination showed they were compatible with malignancy, and immunohistochemistry testing confirmed MM metastases. It was decided to continue therapy for the 12 cycles originally proposed, but there was no improvement in the aforementioned lesions. New lesions appeared in subcutaneous tissues and the perianal region, and the patient's clinical condition worsened. He died after two months receiving palliative care.

Keywords: Multiple myeloma; Metastases; Plasmacytoma; Skin neoplasms; Testicular neoplasms (source: MeSH). 


\section{INTRODUCCIÓN}

El mieloma múltiple (MM) se caracteriza por la proliferación descontrolada y clonal de los plasmocitos en la médula ósea, acompañada de la producción de inmunoglobulinas anómalas monoclonales, llamadas proteínas $\mathrm{M}^{[1]}$. Es la segunda enfermedad oncohematológica más común en el mundo, representa el $1 \%$ de todas las neoplasias malignas, con mayor prevalencia en mayores de 50 años ${ }^{[1,2]}$ y una incidencia de 5-10/100 000 personas por año ${ }^{[3]}$. Ocurre preferentemente en hombres, su incidencia aumenta progresivamente con la edad (el $90 \%$ de los pacientes tiene más de 50 años de edad) y la edad media al momento del diagnóstico es de 70 años. ${ }^{[4]}$. La supervivencia media del MM es de 24 a 36 meses, pero en casos sintomáticos y con lesión vertebral disminuye a seis meses ${ }^{[3]}$.

Las complicaciones más comunes del MM son la hipercalcemia, dolor óseo y fracturas en huesos del esqueleto apendicular y axial. Cuanto mayor es el compromiso del estado general y la diseminación de la enfermedad, peor será la sobrevida ${ }^{[3]}$. Raramente afecta a la piel (5 a $10 \%$ de los casos) ${ }^{[5]}$ y la incidencia de casos de plasmocitoma (o lesión solitaria) que afecta a los testículos alcanza entre el $0,6 \%$ y el $2,7 \%$ del total de casos ${ }^{[6]}$. Es poco frecuente que afecte órganos nobles, siendo el hígado uno de los más afectados $(20 \%)^{[3]}$. El diagnóstico se basa en la combinación de características clínicas, laboratoriales e imagenológicas ${ }^{[4,5]}$. El plasmocitoma se diagnostica en sólo el $10 \%$ de estos pacientes.

Aunque la terapéutica ha mejorado, el mayor problema en el MM es la resistencia al tratamiento, siendo la evolución clonal de las células del MM y las alteraciones en el microambiente de la médula ósea las contribuyen a esta resistencia ${ }^{[7]}$. Por esto, y su mal pronóstico, se plantean nuevas opciones terapéuticas entre las que se incluye el trasplante con células progenitoras [2]. Describimos el caso de un paciente varón de 56 años con antecedente de haber padecido MM en columna vertebral (cinco años antes de la atención médica), el cual fue tratado con quimioterapia y trasplante autólogo de médula ósea que permitió la remisión completa. Después de 4 años, presentó recidiva ósea de la enfermedad, además de metástasis en tejido celular subcutáneo y testículos, con comportamiento agresivo y poco sensible al tratamiento.

\section{REPORTE DE CASO}

Paciente varón de 56 años de edad, caucásico, sin historia familiar de cáncer y antecedente de infarto agudo de miocardio. Fue diagnosticado en el año 2013 con mieloma múltiple, estadio IIla, luego de acudir a una institución hospitalaria por presentar un intenso dolor óseo en columna vertebral sin otros síntomas asociados. En dicha hospitalización, presentó un valor de beta 2-microglobulina: $2864 \mathrm{ng} / \mathrm{mL}$, el $60 \%$ de la médula ósea infiltrada por células plasmáticas y electroforesis de proteínas compatible con MM (pico monoclonal con fracción gamma: 9,4 g/dL); además, los estudios de citogenética e hibridación fluorescente in situ (FISH) de médula ósea confirmaron esa patología.

Adicionalmente, el paciente poseía lesiones infiltrantes en toda la columna vertebral y fracturas en T12 y L3, lo que motivó el uso de chaleco Jewwet. Recibió tratamiento quimioterápico con cuatro ciclos de bortezomib (Velcade ${ }^{\circledR}$ ), ciclofosfamida y dexametasona. A finales del 2013 fue sometido a trasplante autólogo de médula ósea, con excelente respuesta. Presentó una remisión de cuatro años.

En el año 2017, el paciente comenzó a padecer múltiples dolores en columna y cadera. Por tal motivo, se realizó una investigación con tomografía computarizada por emisión de positrones (PET CT) (Figuras 1 y 2), en la que se constató una nueva lesión lítica en sacro, la misma que fue diagnosticada como plasmocitoma. No se realizaron otras PET CT para controlar las lesiones. El paciente fue sometido a radioterapia y posterior exéresis de la lesión; además, recibió cuatro ciclos de lenalidomida ( $25 \mathrm{mg}$ - ciclo de 21 días).

Un año después hubo progresión de la enfermedad ósea, razón por la que se inició un nuevo tratamiento quimioterápico con esquema KRd (carfilzomib-pomalidomida-dexametasona) por 12 ciclos de 28 días, además de daratumumab y corticoterapia. El esquema de KRd se realizó con carfilzomib intravenoso $27 \mathrm{mg} /$ $\mathrm{m}^{2}$ en los días 1 (D1), D2, D8, D9, D15, D16 (en el ciclo 1, la dosis de carfilzomib en los D1 y D2 fue de $\left.20 \mathrm{mg} / \mathrm{m}^{2}\right)$, ciclos 1 a 12 ; y lenalidomida $25 \mathrm{mg}$ por vía oral (D1 a D21) y dexametasona 40 mg (D1, D8, D15, D22) que se repitieron cada 4 semanas.

Se observó una evolución desfavorable en los primeros ciclos con la aparición de nódulos en tejido celular subcutáneo en la región dorsal (Figuras 2 y 3) y el puño izquierdo (Figura 4), además de nódulos testiculares. A la evaluación por ultrasonido, tanto los nódulos en tejido celular subcutáneo como los testiculares eran hipoecogénicos, sólidos, con contornos parcialmente regulares y con flujo al doppler, características compatibles con plasmocitoma. Los nódulos testiculares se ubicaban en el tercio medio del testículo izquierdo (con una medida de 10,1 x 3,2 $\times$ $2,7 \mathrm{~cm}$ ), en el tercio superior del testículo derecho (de $0,8 \times 0,3$ $\mathrm{cm}$ ) y en el tercio medio del testículo derecho (de $0,7 \times 0,5 \mathrm{~cm}$ ).

Se realizó la resección de los tumores en el dorso (Figuras 3, 4 y 5) y puño (Figura 4), siendo el estudio anatomopatológico compatible con neoplasia maligna e inmunohistoquímica que confirmaban que se trataba de metástasis de MM. Se eligió no realizar una orquiectomía porque los nódulos testiculares tenían las mismas características de imagen que las lesiones resecadas en tejido celular subcutáneo.

Se optó por mantener el tratamiento hasta completar los 12 ciclos propuestos. No obstante, no hubo remisión de las lesiones descritas, además que surgieron nuevas lesiones en tejido celular subcutáneo en miembro inferior izquierdo y región perianal, con empeoramiento clínico del paciente. El paciente falleció después de dos meses de cuidados paliativos. 


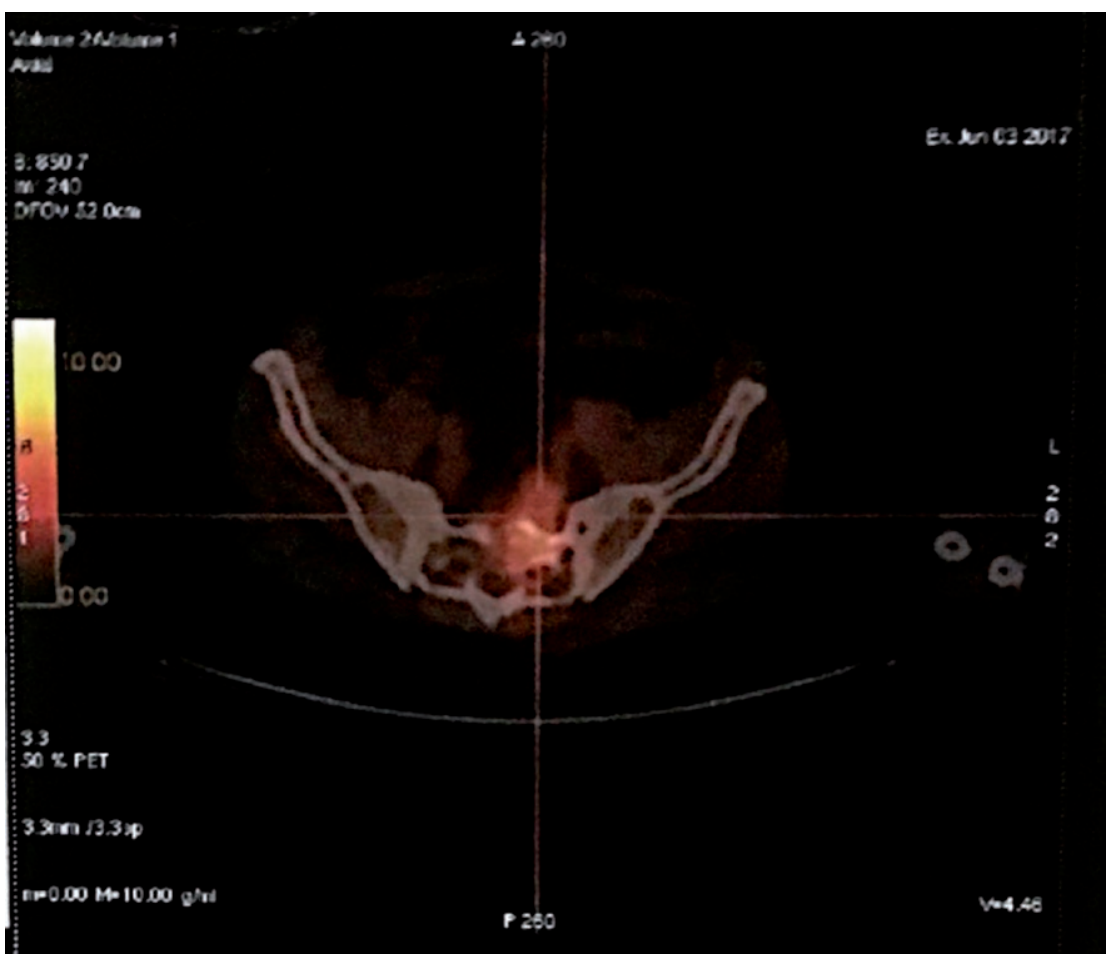

Figura 1. Tomografía por emisión de positrones - tomografía computarizada (PET-CT) realizada un año antes de la atención descrita el en reporte. Se muestra una lesión lítica en sacro (S1 - S2) notablemente a la izquierda, con valor de captación estándar máximo de hasta 5,31 y estructura con densidad de partes blandas asociada en la región presacra izquierda, una medida de 21 x $32 \mathrm{~mm}$ y un valor de captación estándar máximo de hasta 4,46.

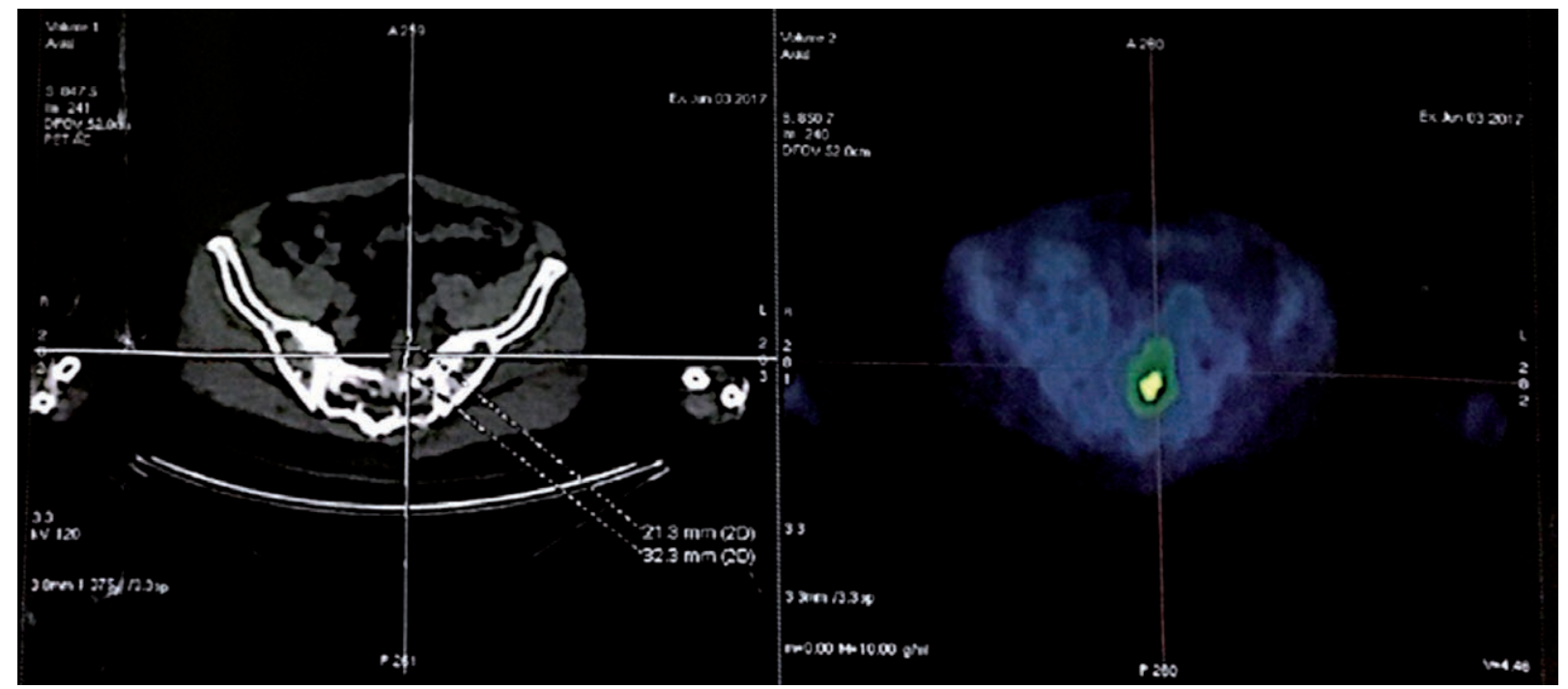

Figura 2. Tomografía por emisión de positrones - tomografía computarizada (PET-CT) realizada un año antes de la atención descrita el en reporte. Se muestra lesión lítica en sacro (S1 - S2).

\section{DISCUSIÓN}

En la evolución del MM, inicialmente las lesiones neoplásicas se restringen a la médula ósea y al hueso, siendo tardío el compromiso extramedular ${ }^{[6]}$. Las neoplasias de células B comprometen inicialmente a los ganglios linfáticos y la médula ósea, luego se diseminan hacía la piel y otros órganos ${ }^{[9]}$.
Raramente el MM tiene afectación cutánea (del 5 al 10\% de los casos), las cuales pueden clasificarse en lesiones específicas e inespecíficas ${ }^{[5]}$. Las lesiones cutáneas específicas son los plasmocitomas secundarios que pueden ocurrir por diseminación hematógena o por extensión directa a partir de lesiones óseas subyacentes ${ }^{[5]}$, como fue en el caso de nuestro paciente. La cavidad oral, vías aéreas superiores, tracto gastrointestinal 


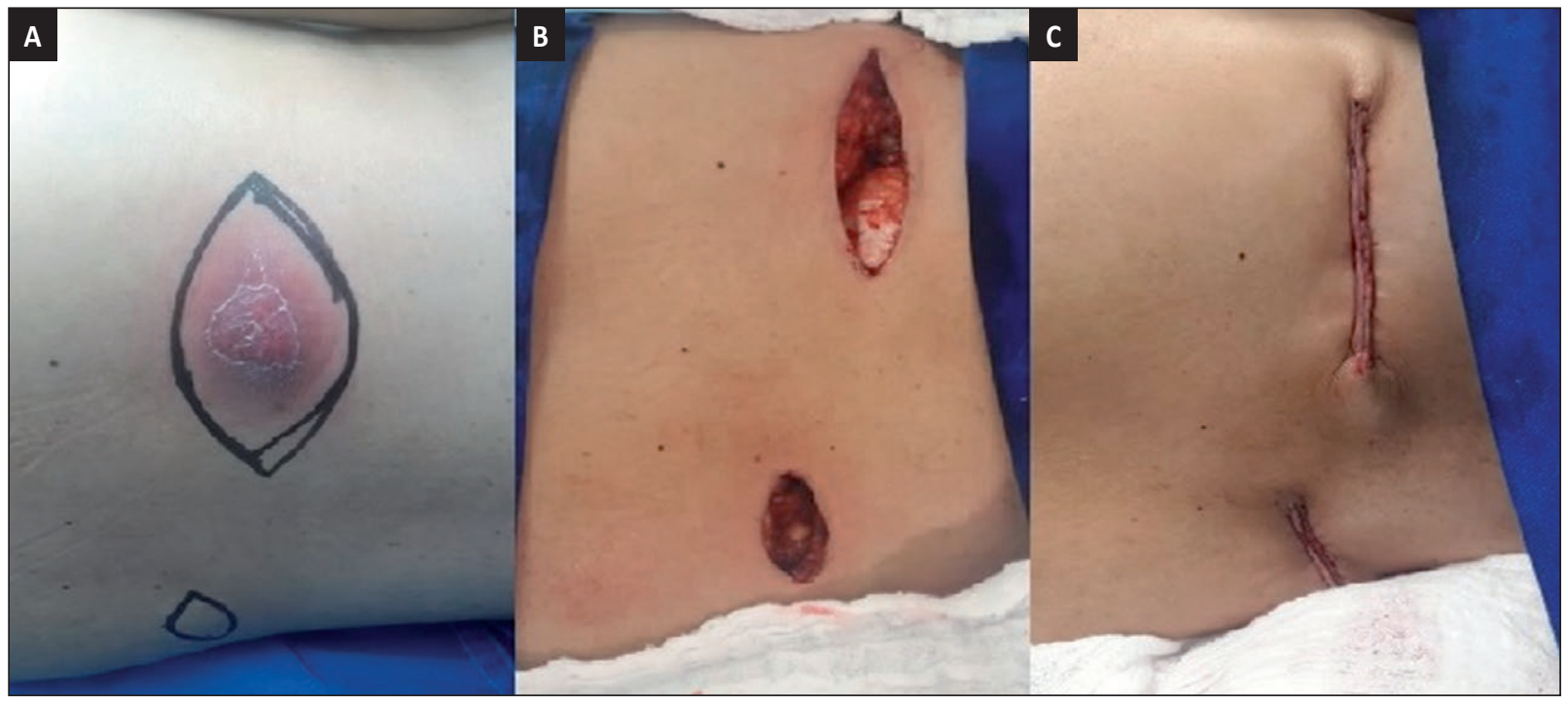

Figura 3. Aspecto macroscópico de las lesiones en dorso A. antes, B. durante y C. después de la resección de las masas tumorales.

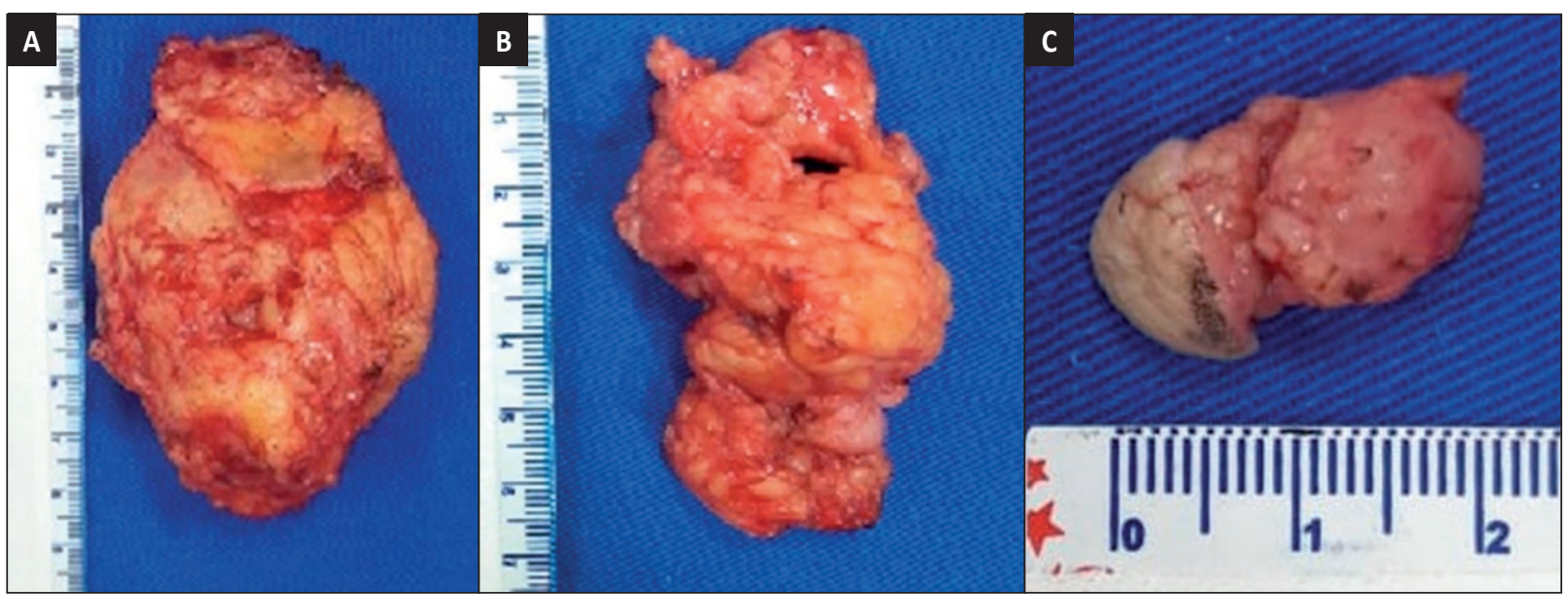

Figura 4. Aspecto macroscópico de la lesión en A. dorso, lado izquierdo, B. dorso, lado derecho y C. puño izquierdo.

y los ganglios linfáticos son los lugares más frecuentemente involucrados ( $80 \%$ de los casos) ${ }^{[10]}$; estos ocurren generalmente en fases tardías de la enfermedad, como un reflejo de la elevada carga tumoral ${ }^{[3,5]}$. Las lesiones cutáneas inespecíficas incluyen amiloidosis, vasculitis leucocitoclásica, crioglobinemia tipo I, síndrome de Sweet, pioderma gangrenoso, xantomas planos, dermatosis pustulosa subcorneal, escleromixedema y xantogranuloma necrobiótico ${ }^{[5,10]}$.

Los plasmocitomas secundarios por extensión directa de la piel son los más comunes, siendo nódulos de consistencia blanda a la palpación y normocrómicos ${ }^{[5]}$. Los plasmocitomas por diseminación hematógena se presentan como nódulos en tejido celular subcutáneo o intradérmicos violáceos, son de consistencia dura y aparecen tardíamente en el curso de la enfermedad ${ }^{[5]}$. Las localizaciones más comunes de los nódulos cutáneos o subcutáneos en el MM son el tronco, extremidades y la cara ${ }^{[5]}$. En nuestro paciente se observaron tres lesiones nodulares, siendo una de coloración eritrotoviolácea, sin ulceración; dos en dorso y una en puño izquierdo, lo que sugirió diseminación hematógena.

Adicionalmente, pueden haber plasmocitomas cutáneos primarios, los cuales ocurren sin compromiso de la médula ${ }^{[11]}$. Estos tumores son raros (representan entre el 3 y $12 \%$ de los casos de plasmocitomas extramedulares). tienen un pronóstico variable, pudiendo o no ocurrir diseminación de la enfermedad ${ }^{[1]}$.

El tratamiento generalmente incluye la combinación de quimioterapia, radioterapia local y/o escisión quirúrgica ${ }^{[10]}$. Estas lesiones son una señal de mal pronóstico de la enfermedad, pues el $50 \%$ de los casos llega a fallecer en un periodo de hasta 12 meses luego del diagnóstico ${ }^{[5]}$. En el caso presentado, el tratamiento fue la combinación de quimioterapia y escisión quirúrgica de algunas lesiones. Nuestro paciente evolucionó con metástasis en tejido celular subcutáneo y el testículo antes de completar el esquema quimioterápico de 12 ciclos, falleció en un período inferior a 12 meses de la aparición de nuevas lesiones. 
Los testículos también pueden verse afectados (plasmocitoma testicular) por el MM, aunque en una baja proporción (representa el $2 \%$ de todas las neoplasias de células del plasma) ${ }^{[6]}$. Su incidencia se encuentra entre el $0,03 \%$ y el $0,1 \%$ de todos los tumores primarios y secundarios que afectan el testículo ${ }^{[6]}$. Entre los pacientes con $\mathrm{MM}$, la incidencia está entre el 0,6\% y el 2,7\% del total ${ }^{[6]}$. Una revisión de 37 casos de plasmacitoma testicular mostró que más del $80 \%$ tenían mieloma múltiple concomitante ${ }^{[6]}$.

El plasmacitoma testicular puede ser primario o metastásico (siendo el caso del paciente en cuestión); afecta al parénquima testicular, aunque ocasionalmente también puede aparecer en el epidídimo. Se presenta con hinchazón indolora y algunas veces se asocia a hidrocele. Histológicamente, se manifiesta con la presencia de células plasmáticas atípicas y las técnicas de inmunohistoquímica muestran la expresión de inmunoglobulinas citoplasmáticas ${ }^{[6]}$. El diagnóstico diferencial de un plasmocitoma testicular debe realizarse especialmente con seminomas espermatocíticos y con linfomas; su pronóstico varía cuando está asociado o no al mieloma múltiple ${ }^{[12]}$.

El pronóstico de los pacientes con plasmacitoma testicular y MM es malo, con una sobrevida postoperatoria que varía de cinco semanas a cuarenta y ocho meses, siendo la supervivencia media de apenas 12 meses ${ }^{[13]}$.

El tratamiento estándar para el plasmacitoma testicular es la orquectomía radical. Los estudios demostraron que la quimioterapia y la radiación no tuvieron éxito ${ }^{[14]}$; aunque, puede considerarse el uso de radiación local en pacientes con resección incompleta o con enfermedad recurrente o refractaria ${ }^{[15]}$. Existen algunos casos vivieron años después de la orquectomía, sin evidencia de enfermedad plasmocitaria sistémica ${ }^{[13]}$. En el caso que presentamos, no se realizó la escisión de la metástasis testicular debido al mal pronóstico y la aparición de múltiples nuevas lesiones provenientes del MM.

En conclusión, reportamos un caso raro de mieloma múltiple con plasmocitomas en tejido celular subcutáneo y testículo. Esta patología es más común en hombres y la incidencia aumenta progresivamente con la edad (la mayoría de los casos ocurre a partir de los 50 años). El tratamiento de los plasmocitomas cutáneos generalmente incluye la combinación de quimioterapia, radioterapia local y/o escisión quirúrgica. El tratamiento estándar para el plasmacitoma testicular es la orquectomía radical. En este caso, el paciente de 56 años tuvo recidiva en sacro y plasmocitomas en tejido celular subcutáneo y testículo incluso después del tratamiento quimioterápico y trasplante autólogo de médula ósea. El paciente descrito fue sometido a varias formas de tratamiento del MM; sin embargo, presentó recidiva metastásica rara y comportamiento extremadamente agresivo que no respondió a terapéutica alguna. El paciente falleció después de dos meses de cuidados paliativos.

\section{REFERENCIAS BIBLIOGRÁFICAS}

1. Paula e Silva RO, Brandão KMA, Pinto PVM, Faria RMD, Clementino NCD, Silva CMF, et al. Mieloma múltiplo: características clínicas e laboratoriais ao diagnóstico e estudo prognóstico. Rev Bras Hematol Hemoter. 2009;31(2):63-8.

2. Funari MFA, Guerra JCC, Ferreira E, Pasternak J, Borovik CL, Kanayama RH, et al. Mieloma Múltiplo: 50 casos diagnosticados por citometria de fluxo. Rev Bras Hematol Hemoter. 2005;27(1):31-6.

3. Avanzi O, Landim E, Meves R, Silver MF, Vaz de Lima M. Fratura na coluna vertebral por mieloma múltiplo: correlação entre sobrevida e índices de Tomita e Tokuhashi. Coluna/Columna. 2009;8(1):73-9. doi: 10.1590/S1808-18512009000100014

4. Magalhães MCP. B2-microglobulina nos doentes com mieloma múltiplo [Tesis de Maestría]. Lisboa, Portugal: Universidade Católica Portuguesa; 2012.

5. Ferreira de Souza DA, Proença de Freitas TH, Pinto RA, Müller $H$, Hungria VTM. Mieloma múltiplo com plasmocitomas cutâneos. An Bras Dermatol. 2004;79(5): 581-5.

6. Garrido O, Coloma A, Bocardo G, Jiménez M, Herranz LM, Arellano $\mathrm{R}$, et al. Plasmocitoma testicular bilateral secundario: Aportación de un caso y revisión de la literatura. Actas Urol Esp. 2008;32(10):103942.

7. Wen.Chi Y, Sheng.Fung L. Mechanisms of drug resistance in relapse and refractory multiple myeloma. Biomed Res Int. 2015;2015:341430.

8. Angtuaco EJ, Fassas AB, Walker R, Sethi R, Barlogie B. Multiple myeloma: clinical review and diagnostic imaging. Radiology. 2004;231(1):11-23.

9. Alberts DS, Lynch P. Cutaneous plasmacytomas in myeloma: relationship to tumor cell burden. Arch Dermatol. 1978;114(12):17847. doi: 10.1001/archderm.1978.01640240026007

10. PEREIRA, N. et al. Plasmocitoma cutâneo metastático em doente com mieloma múltiplo. Revista SPDV. 2012;70(3):387-90. doi: 10.29021/spdv.70.3.19

11. Belinchòn I, Ramos J. M, Onrubia J, Mayol MJ. Primary cutaneous plasmocytoma in a patient with chronic lymphatic leukemia. J Am Acad Dermatol. 1996;35(5 Pt 1):777-8. doi: 10.1016\%2Fs01909622(96)90750-1

12. White J, Chan YF. Solitary testicular plasmacytoma. Br J Urol. 1995;75(1):107-8. doi: 10.1111/j.1464-410x.1995.tb07252.x

13. Shafqat A, Yum MN, Abanour R, Ganjoo KN. Unusual locations of involvement by malignancies: Case 1. Testicular plasmacytoma. J Clin Oncol. 2003;21(17):3368-9. doi: 10.1200/JCO.2003.09.049

14. Pham TH, Shetty SD, Stone CH, De Peralta-Venturina M, Menon M. Bilateral synchronous testicular plasmacytoma. J Urol. 2000;164(3 Pt 1): 781. doi: 10.1097/00005392-200009010-00042

15. Tanagho Y, Stovsky M, Maclennan GT. Testicular plasmacytoma. J Urol. 2010;184(3):1161-2. doi: 10.1016/j.juro.2010.06.031 